\title{
Psychological culture of a modern university teacher as a determinant of student development (in the context of teaching students of agricultural orientation)
}

\author{
Galina Zvezdina ${ }^{1}$, Anastasia Grishina ${ }^{1, *}$ \\ ${ }^{1}$ Don State Technical University, 1, Gagarin sq., 344003, Rostov on Don, Russia
}

\begin{abstract}
The article presents the generalized experience of studying the psychological culture of university teachers. Authors sustained the relevance of the problem on the example of teaching specialists for the agro-industrial complex and updated the basic requirements for modern agro-industrial specialists. The article gives a review of methodological foundations of studying the psychological culture: the analysis of approaches to the definition of "psychological culture", the components of the psychological culture and the levels of its development, the features of the psychological culture of teachers. Authors reveal the specifics of the professional activity of a higher education teacher in the context of the personality-oriented education implementation by providing an emprical study. The procedure of empirical research to study the components of the psychological culture of university teachers with different lengths of pedagogical activity is described. The results of an empirical study aimed at studying the following components of psychological culture are described in detail: affective (empathy), communicative (social communicative competence) and value-semantic (communicative tolerance) and an integral indicator of the cultural and psychological potential of university teachers. Authors show the features of the formation of communicative competence, empathy, communicative tolerance depending on the length of pedagogical activity.
\end{abstract}

\section{Introduction}

In the conditions of innovative transformations of modern society, education is the vanguard of change. The psychological culture of the teacher at the present stage of the higher education modernization is one of the basic components in the system of providing educational services to the consumer, meeting the demand of modern production.

The concept of psychological culture is reflected in interdisciplinary research, in the works of psychologists, teachers, philosophers, sociologists, both in domestic and in foreign science and practice.

* Corresponding author: avgrishina.donstu@gmail.com 
The modern educational paradigm has led to an increase in the relevance of humanistic approaches to education based on a personality-oriented concept of vocational training of a graduate, which leads to the need of improving the psychological culture of educational subjects, to the formation of teachers' psychological competence.

The training of specialists in the agro-industrial complex, as well as in other branches of production, is at the epicenter of educational transformations. The needs of agro-industrial production for a qualitatively new innovatively-oriented workforce come to the fore $[1,2]$. A modern agricultural worker, first of all, must have a certain level of systemic thinking, environmental thinking, willingness to change, creativity, ability to take responsibility and make decisions in the rapidly changing conditions of the modern environment. So-called flexible skills, or soft skills, are becoming more in-demand in modern professional activities. The formation of ecological culture among future specialists in the agricultural sector is an important problem. [3] With this orientation of education, an actualized personality-oriented approach to each student requires the necessary level of psychological culture from the university teacher.

\section{Methods}

The psychological culture of the university teacher was studied by Abakumova I.V., Alexandrova N.V., Belova N.Yu., Volkova K.P., Demina L.D., Zvezdina G.P., Ilyina V.S., Kamenskaya E.N., Kolmogorova L.S., T. Kulikova, Gyurova V., Zeleeva V., Lezhenina A.A., Matolygina N.V., Piskunova A.I., Semikina V.V., Sladkova I.A., Chirkova T.I. et al. $[2,3,4,5,6,8,9]$.

Psychological culture is the basis of personality culture as a synergistic integrity of a person. The psychological culture in the field of education provides individuals with the opportunity to effectively self-determine in pedagogical society, to realize themselves in professional and personal development, to master the techniques of successful social adaptation to any institutional environment.

N.T. Selezneva identifies four groups of approaches to the study of psychological culture. The first group consists of studies that reflect individual aspects, structural components of the individual psychological culture (Semikin V.V., Demina L.D., Kuzmina A.B.). The second group is determined by research, which is based on integrative personality traits that allow one to realize his identity and, while maintaining it when interacting with other identity, realize creative potential, self-actualize (Pevzner N.Yu., Lezhenina A.A., Levkova E .A., Oparina N.M.). The third group includes studies aimed at studying pedagogical conditions, developing active methods, psychological and acmeological tools, various psychotechnologies and other factors of activating the individual's creative potential, addressing the phenomenal manifestations of the human psyche, self-regulation, expanding the space of your identity (Zorin S. S., Melnichuk S.S.). The fourth group of studies considers psychological culture as a means of effectively performing any type of activity (Matolygina N.V., Ruglova L.V.) $[5,6,7$ 9, 10].

Psychological culture, as a systematic formation of personality, includes the following structural components: value-semantic, cognitive, communicative, affective, volitional regulatory, reflective-perceptive, an experience of social interaction (Semikin V.V.). A certain group of scientists associates the teacher's psychological culture with pedagogical creativity (Kolmogorova L.S., Motkov O.I., Vilkeev D.V., Kashapov M.M., Korneeva N.N., Orlov A.B. E.A., Shmeleva et al.) The creative approach is one of the basic components in the multifaceted palette of psychological and pedagogical culture. Other scientists study communicative culture in the general context of psychological and pedagogical culture $[4,5,8,11,12]$. 
Psychological culture is expressed in the ability to self-regulate actions and emotions, in constructive communication, in expressed processes of self-determination, creativity and self-development of a person.

The teacher's psychological culture is understood as a synthesis of relevant psychological knowledge necessary for teaching your subject (psychodidactic knowledge), the possibilities for productive professional and personal communication with students, as well as in the presence of a conscious need to improve your professionalism [13].

In the development of psychological culture V.V. Semikin distinguishes three levels:

- psychological literacy as some minimum psychological knowledge and skills that provide more or less adequate behavior and social interaction;

- psychological competence, ensuring the effectiveness of behavior, activities or social interaction with people;

- mature psychological culture, as a developed mechanism of personal self-regulation, which provides effective, safe and humane interaction with people.

Psychological culture as a basic component of the modern education humanization integrates the whole range of concepts, approaches and theories that are fully implemented in the process of professional communication.

The traditional approach to teaching at the university provided a number of criteria for teachers to carry out educational activities, the main of which was the presence of a higher education in a specialty, academic degree, academic title, work experience - but there were no criteria for the availability of pedagogical or psychological education in this hierarchy.

The psychological culture of the university teacher can be fully externalized in the conditions of cooperation pedagogy and psychological safety, where the teacher and student act as like-minded partners in the production and reproduction of knowledge, creating scientific and social projects for students, undergraduates and graduate students. [14].

The ideas of a personality-oriented approach were actively included in pedagogical practice by the founder of the humanistic direction in psychology, Karl Rogers. He is also considered to be a founder of the "non-directive pedagogy". He believed that the maximum educational effect can be achieved only in an atmosphere of creative cooperation between the teacher and students, when conditions are created for the most complete disclosure of students' abilities.

Within the framework of this concept, R. Sternberg positions the triarchic theory of successful intelligence, based on the maximum development of students' analytical, creative and practical abilities. This theory of successful intelligence will become the basis for the preparation of bachelors and masters both in humanitarian and technical fields of education.

Prominent russian psychologist I. Dubrovina notes that "Higher professional education of any profile should more consistently affirm the humanistic, cultural orientations of human existence, educate the psychological culture of specialists whom it brings to life, thereby gradually restoring the cultural potential of modern society" [15].

The basic elements of the teacher's psychological culture include pedagogical communication, pedagogical abilities, pedagogical thinking, pedagogical goal-setting, pedagogical intuition, improvisation, emotional intelligence, observation, resourcefulness, pedagogical facilitation and reflection.

\section{Results and discussion}

A modern teacher, acting as a learning motivator, should interest the student, show him the range of possibilities for his future professional realization. Studying at a university, in the conditions of new requirements for agricultural specialists, combines research and development aimed at developing new technologies for the agricultural sector, on the one 
hand, and practice-oriented, on the other. Practical orientation includes the orientation of students to a modern production request and taking into account the individual characteristics of students, which he will be able to apply in various fields of agriculture. This is especially true for teachers conducting practical classes, as they are regularly contacting the students. They will notice more individual differences of students, their professional orientation, great scientific orientation or practice-oriented, and personal qualities such as responsibility, willingness to change, communication skills, and the ability to make decisions.

The task of the teacher at this moment is to show tolerance and empathy for the student, to find forms of work through which he will believe in himself, in his strength, in his own success. During this period, you can think of playful, entertaining forms of activity, because they maximally contribute to personal self-determination. When passing the test or exam, the teacher should remember that an overvaluation or «credit of trust» can have the most beneficial effect on the emotional state, on some insight, which will trigger a mechanism to stabilize the student's psychological health.

Non-traditional teaching methods focused on the activity and independence of students are newsworthy in our opinion. Innovative types of classes are gaining more and more popularity, during which students can master, consolidate or learn educational material in an entertaining way. For example, a lesson in the form of a quest on a subject can be aimed both at studying new material and at consolidation. At the same time, empirical immersion of students in educational material will contribute to better learning and memorization of the course content block, and team work of students will contribute to enhancing the potential of the «brainstorming» method during the classroom. Game pedagogy at this stage expands the boundaries of pedagogical interaction, and modern popular technologies of society can become an effective tool to improve the quality of the educational process in a university.

Thus, the modern social environment has led to the emergence of factors that must be taken into account in the work of the university teacher.

In this regard, the need for the university teacher to understand the psychological characteristics of students and to take into account the specifics of their behavior is growing. A modern university teacher needs to master the basics of psychological culture in order to implement the educational mission more effectively and to realize oneself and one's place in this process.

In the course of this scientific study, the first stage of an empirical study was conducted with the teaching staff of universities in Rostov-on-Don, the total sample was 66 people. The subject of the study was the components of psychological culture that ensure the effectiveness of pedagogical communication, social interaction with students, the level of realization of cultural and psychological potential in professional activities. The age range of respondents is from 24 to 55 years, with the experience of teaching in a university from 1 year to 27 years.

The aim of psychological diagnostics is to study the affective (empathy), communicative (social communicative competence) and value-semantic (communicative tolerance) components of psychological culture and an integral indicator of the cultural and psychological potential of university professors, of different professional profiles.

The study was carried out using observation, interview, psychological diagnosis. The following methods were used: «Test of communicative social competence», «Questionnaire of communicative tolerance» (by V.V. Boyko), «Test of empathic abilities level» (by V.V. Boyko), «Test Cultural and psychological potential» (by O.I. Motkova) 


\section{The discussion of the results}

A study of the level of teachers' social communicative competence showed that the level of communicative competence of $62.4 \%$ of teachers is within average values, $3.2 \%$ of respondents showed a low level of communicative competence and a third $(31.2 \%)$ of respondents showed a high level of competence.

The analysis of the diagnostic results depending on the length of professional activity showed some regularity: the most pronounced social and communicative competence was found in the group of teachers with a long experience in professional activity, $34 \%$ of teachers with 10-20 years of experience and $31.2 \%$ with a teaching experience of 20 years or more have a high level of communicative competence.

Table 1. The level of communicative competence of university teachers with different lengths of pedagogical activity.

\begin{tabular}{|c|c|c|c|}
\hline & $\begin{array}{c}\text { Teachers with } \\
\text { experience up to 10 } \\
\text { years (in \%) }\end{array}$ & $\begin{array}{c}\text { Teachers with 10-20 } \\
\text { years of experience (in } \\
\text { \%) }\end{array}$ & $\begin{array}{c}\text { Teachers with more } \\
\text { than 20 years of } \\
\text { experience } \\
\text { (in \%) }\end{array}$ \\
\hline high & 6.2 & 34 & $31.2 \%$ \\
\hline medium & 16 & $17.4 /$ & $30.2 \%$ \\
\hline low & 3.2 & - & - \\
\hline
\end{tabular}

We conducted an analysis for the presence of a relationship between indicators of psychological culture using the Pearson correlation coefficient. The results obtained indicate that communicative competence depends on the length of professional activity $(\mathrm{r}=$ 0.43 , with $\mathrm{p}<0.05$ ): the higher the length of professional activity, the higher the level of communicative competence.

The study of the ability to empathy among teachers allowed us to determine the severity of the affective component of psychological culture. Following the authors of the methodology, we mean empathy as an emotional response to the experiences of another person, manifested in empathy and sympathy.

About $30 \%$ of respondents showed a reduced level of empathy. Such teachers may allow pedagogical tactlessness, moralizing in behavior. They are not always capable and ready to take the student's position and understand his situation.

The results of the study showed that teachers with different lengths of professional activity have uneven channels of empathy. Teachers with a long experience of professional activity have a more pronounced emotional channel of empathy, which is 4.2 points. Teachers with experience up to 10 years have more pronounced penetration ( 3.7 points), which manifests itself in creating a situation of openness, trust, understanding. This group is represented by young teachers, who are closest in age to the student audience and more disposed to informal communication. Low indicators on empathy channels were identified by a rational channel ( 2.7 points) in a group of teachers with more than 20 years of teaching experience. The rational channel of empathy characterizes the focus of attention, perception and thinking empathizing on the essence of any other person - on his condition, problems, behavior. This is a spontaneous interest in another, opening the gateways of the emotional and intuitive reflection of the partner. Orientation of teachers to the cognitive component of activity often leads to anonymization of ignoring students as active subjects of pedagogical interaction, which can explain the insufficient level of severity of the rational channel.

The study of communicative tolerance showed that $27 \%$ of respondents have a low level of communicative tolerance. This group of subjects included older educators (45 years or more). About a quarter of the respondents (24\%) showed high results in communicative tolerance (the average age of this group is 32 years), $59 \%$ of the studied teachers went to the average values of this indicator (the average age in this group was 42 years). 
Thus, this study showed that the communicative tolerance of university teachers decreases with age, that may indicate professional fatigue and deformation of teachers.

Studying the correlation between the pedagogical experience, the presence of psychological and pedagogical training and the studied personality parameters, showed that the higher the pedagogical experience of the teaching staff, the lower the level of general communicative tolerance $(\mathrm{r}=-0.51)$. At the same time, the maximum values in terms of empathy were observed in a group with a pedagogical experience of up to 20 years. Moreover, the empathy indicators of teachers with psychological and pedagogical education are higher compared to teachers who do not have special psychological and pedagogical education.

At the next stage of empirical research, we studied the components of the cultural and psychological potential: the ability to introspection, ability for constructive communication, ability for psychological self-regulation, ability for creativity, ability for business behavior, ability for self-education and self-development.

The study of the components of the cultural and psychological characteristics of teachers showed that 3 groups of respondents with different lengths of pedagogical activity did not reveal significant differences in the severity of indicators. Though we identified some trends in the severity of the components of the psychological culture. It has been established that among young teachers, the ability for psychological self-regulation and the ability to realize self-realization at the level of feasibility is more pronounced than for teachers with an experience over 20 years.

Interesting results were obtained when assessing creativity: for $60 \%$ of respondents creativity and the level of feasibility of creative abilities remained unchanged, $40 \%$ of teachers with less experience had a increased level of creative realization, and $40 \%$ of teachers with more than 20 years of experience, on the contrary, had a decreased level. This fact can be explained by the presence of a large amount of paper work, routine, and fatigue, which can be a factor that reduces the creative orientation of teachers.

In terms of «constructive communication», there is also some controversy. Among more than $70 \%$ of teachers the level of feasibility of constructive communication has increased compared with the level of natural abilities. However, about $30 \%$, both teachers with experience of up to 20 years, and beginners have shown a decrease in indicators of constructive communication. The results can be explained by professional stagnation and unwillingness to change.

A study of the relationship between communicative tolerance and indicators of cultural and psychological potential revealed that communicative tolerance has an inverse relationship with the ability to self-knowledge and introspection $((\mathrm{r}=-0.31$, at $\mathrm{p}<0.05)$.

The obtained results indicate that the level of the teacher's psychological culture (based on the results of individual components) depends on the level of his psychological and pedagogical training and the experience of teaching. It can be assumed that the decrease in the empathic attitude of teachers towards students acts as a certain psychological defense against the need to carry out a stream of reporting and methodological work, which sometimes obscures direct contact with students and the possibility of engaging in communication. The formal nature of the classes leads to the distancing of the teacher and student, the loss of interest of the teacher in interpersonal relations with students, and the decrease in pedagogical vigilance and attentiveness.

\section{Conclusions}

The activity of a university teacher is multifaceted: educational, pedagogical, research, educational, and involves a fairly high level of professional activity, which obviously is based on the professional and psychological culture of the teacher. 
When training the specialists for the agro-industrial complex, it is necessary to use actively the resources of the modern educational space, including:

- innovative educational-scientific-production structures, agricultural technology parks, demonstration platforms for new equipment and technologies;

- attracting students to fundamental and applied research.

The focus of higher education on the practical training of students and the willingness of future specialists to use modern agricultural production technologies requires a modern university teacher to continuously improve professional, psychological and pedagogical competence.

Based on the results of an empirical study, we can offer psychological recommendations for the development of the components of psychological culture for university teachers, depending on the length of pedagogical activity:

- for teachers with a pedagogical experience of up to 10 years we can recommend training in communicative competence and business communication. The proposed trainings should help the teacher quickly and correctly navigate in the conditions of an external communication situation, learn to understand the psychological state of students by external signs, and acquire skills to manage their own emotions;

- for teachers with an experience of 10 years or more, it is recommended to conduct trainings on the prevention of emotional burnout, increasing psychological resistance to the destructive influence of professional activity, learning relaxation techniques;

- for teachers of the agro-industrial complex and other non-humanitarian profiles, it's recommended to undergo advanced training in the psychological and pedagogical cycle, to expand the arsenal of active teaching methods and techniques that allow building constructive relationships with students, and to support educational, research and practiceoriented projects.

The variety of requirements for a modern university teacher stimulates the process of continuous personal and professional growth and orientates the teacher to new professional standards. Thus, the possession of a complex of professional competencies and the presence of psychological culture will allow the university teacher to create a favorable learning regime for the student audience and will contribute to their research activity and personal self-realization.

\section{References}

1. V.I. Trukhachev, I.Y. Sklyarov, J.M. Sklyarova, L.A. Latysheva, H.N. Lapina, International Journal of Economics and Financial Issues 6(5), 33-41 (2016)

2. A. Khozhanova, G. Zvezdina, M. Elagina, E. Zvezdina, Strategic management of an educational organization of a technical and professional orientation in the context of integration processes in the post-Soviet educational space (2019) //https://www.shsconferences.org/articles/shsconf/abs/2019/11/shsconf_ictdpp2018_02 006/shsconf_ictdpp2018_02006.html

3. M.B. Kalashnikova, S.A. Kuptsova, Psychological-Educational Studies 3 (2009)

4. N.Yu. Belova, Modern Research of Social Problem 43(11), 76-87 (2014)

5. E.A. Shmeleva, Higher education today 6, 37-39 (2010)

6. V. Gyurova, V. Zeleeva, Section Education and Educational Research (2014) https://doi.org/10.1016/j.sbspro.2014.12.40

7. G.P. Zvezdina, N.I. Chernysheva, Actual aspects of the psychological and pedagogical culture of a teacher at a university. Actual issues of social pedagogy and psychology: theory and practice (Cheboksary, 2019) 
8. N.V. Matolygina, L.V. Ruglova, Vestnik of KemSU 2(542), 110-113 (2013)

9. T. Kulikova, Psychology in Russia: State of the Art 5(2) (2012) DOI: 10.11621/pir.2012.0029

10. E.I. Pilyugina, O.N. Taranenko, I.E. Romanko, European science review (2016) https://cyberleninka.ru/article/n/formation-of-psychological-culture-of-theprofessional-as-criterion-and-level-of-its-development

11. D.Yu. Mutanova, K.M. Berkimbayev, Mediterranean Journal of Social Sciences 5(20) (2014) DOI: 10.5901/mjss.2014.v5n20p2726

12. B.J. Buiskool, and others, Key competences for adult learning professionals. Contribution to the development of a reference framework of Key competences for adult learning professionals. Final report (Zoetermeer, 2010)

13. N.I. Smakovskaya, Scientific Sheets. Humanities Series 20(191).23, 225-23 (2014)

14. T. Shcherbakova, D. Misirov, M. Akobyan, I. Zhitnaya, SHS Web of Conferences 72 , 03010 (2019) DOI: https://doi.org/10.1051/shsconf/20197001015

15. I.V. Dubrovina, Vestnik of Minin University 1 https://vestnik.mininuniver.ru/jour/article/view/358?locale=en_US 